\section{OPEN ACCESS}

Ricardo Madrigal-Burgaleta,

Barts Health NHS Trust,

United Kingdom

Reviewed by:

Baruch Jakubovic,

Humber River Hospital, Canada

Emilio Solano Solares,

Ramón y Cajal University

Hospital, Spain

*Correspondence:

Javier Fernández-Sanchez

fj.fernandez@umh.es

Specialty section:

This article was submitted to

Drug, Venom \& Anaphylaxis,

a section of the journal

Frontiers in Allergy

Received: 28 September 2021 Accepted: 17 December 2021

Published: 12 January 2022

Citation:

Jimenez-Rodriguez TW, Manuel

Marco de la Calle F, Lozano-Cubo I, Montoyo-Anton RA, Soriano-Gomis V,

Gonzalez-Delgado P, Burgos-San José A, Climent-Ballester $S$,

Martínez-Banaclocha N and

Fernández-Sanchez J (2022)

Converter Phenotype: A New Profile

That Is Not Exclusive to Taxanes.

Front. Allergy 2:785259.

doi: 10.3389/falgy.2021.785259

\title{
Converter Phenotype: A New Profile That Is Not Exclusive to Taxanes
}

\begin{abstract}
Teodorikez Wilfox Jimenez-Rodriguez ${ }^{1,2}$, Francisco Manuel Marco de la Calle ${ }^{3}$, Inmaculada Lozano-Cubo ${ }^{4}$, Rosa Ana Montoyo-Anton ${ }^{5}$, Victor Soriano-Gomis ${ }^{1,2}$, Purificación Gonzalez-Delgado ${ }^{1,2}$, Amparo Burgos-San José ${ }^{6}$, Seira Climent-Ballester ${ }^{6}$, Natividad Martínez-Banaclocha ${ }^{4}$ and Javier Fernández-Sanchez ${ }^{1,2 *}$
\end{abstract}

${ }^{1}$ Allergy Section, Alicante General University Hospital, Alicante Institute for Health and Biomedical Research (ISABIAL), UMH, Alicante, Spain, ${ }^{2}$ Spanish Research Network on Asthma and Adverse and Allergic Reactions (ARADyAL) Spanish Network (RD16/0006), Instituto de Salud Carlos III, Fundación Española para la Ciencia y la Tecnología, Madrid, Spain, ${ }^{3}$ Immunology Service, Alicante General University Hospital, Alicante Institute for Health and Biomedical Research (ISABIAL), Alicante, Spain, ${ }^{4}$ Oncology Section, Alicante General University Hospital, Alicante Institute for Health and Biomedical Research (ISABIAL), Alicante, Spain, ${ }^{5}$ Oncology Day Hospital Nursing Service, Alicante General University Hospital, Alicante Institute for Health and Biomedical Research (ISABIAL), Alicante, Spain, ${ }^{6}$ Pharmacy Department, Alicante General University Hospital, Alicante Institute for Health and Biomedical Research (ISABIAL), Alicante, Spain

Introduction: Phenotype I hypersensitivity reactions are the most commonly reported drug reactions; however, precision medicine has made it possible to characterize new phenotypes. A recent communication proposed the existence of a "converter phenotype," which would affect patients who present non-immediate hypersensitivity reactions and in subsequent exposures develop immediate hypersensitivity reactions. This study aimed to describe the clinical characteristics of converter phenotype reactions and their evolution during desensitization to chemotherapeutic drugs and monoclonal antibodies.

Methods: We retrospectively reviewed our database of patients undergoing desensitization to chemotherapy or biological agents and selected those with a converter phenotype. Demographic and clinical characteristics of the patients, the results of skin tests, tryptase and IL-6 levels, and desensitization outcomes were assessed.

Results: Of 116 patients evaluated, 12 (10.3\%) were identified as having a converter phenotype. The median interval between drug exposure and reaction was $90.6 \mathrm{~h}$ (range 8-288 h). After the conversion, phenotype I was the most frequent (58.3\%), followed by cytokine release reactions (33.3\%). Fifty-one desensitizations were undertaken and all treatments completed, with 10 (19.6\%) breakthrough reactions. No new changes in the phenotype were detected.

Conclusions: The symptoms of non-immediate drug hypersensitivity reactions may indicate the need for an early allergological evaluation to assess the risk of future immediate drug reactions. Clinical characteristics, skin test results, and biomarkers can help predict responses to rapid drug desensitization, guiding clinicians on how to optimize therapy delivery while maintaining patient safety.

Keywords: rapid drug desensitization, hypersensitivity, oncoimmunology, chemotherapy (CH), monoclonal antibodies (immunology), desensitization and challenge, drug allergy, drug hypersensitivity reaction (DHR) 


\section{INTRODUCTION}

Phenotype I (PhI) reactions are the most commonly reported kinds of drug hypersensitivity reactions (DHR) according to the Gell and Coombs' classic description; however, precision medicine has brought to light other types that had no place into this classification, such as cytokine release reactions (1). Gell and Coombs' classification also left out some phenotypes of nonimmediate drug hypersensitivity reactions (NIDHR), including accelerated reactions $(2,3)$.

NIDHR occur any time as from $1 \mathrm{~h}$ after the initial drug administration, frequently appearing after many days of treatment (4), and include both accelerated reactions that appear 1-48 $\mathrm{h}$ after exposure to the drug and delayed reactions which occur after $72 \mathrm{~h}(2,3)$. Although NIDHRs are less frequent than their immediate counterparts (IDHRs), they represent a diagnostic and therapeutic challenge because few patients who develop this group of reactions can continue with their first line of treatment (5).

In 2018, preliminary clinical descriptions about a new phenotype of DHRs to taxanes emerged (6). The so-called the "converter phenotype" $(\mathrm{CPh})$ defined a group of taxane-treated patients who initially presented with NIDHRs but developed IDHRs after subsequent exposures, generally $\mathrm{PhI}$ reactions (6).

Previous publications have demonstrated the benefits of rapid drug desensitization for treating several phenotypes, including $\mathrm{PhI}$, cytokine release reactions (CRRs), mixed phenotypes $(\mathrm{MxPh})$ and NIDHRs $(1,7-11)$. Nevertheless, desensitization is contraindicated in Gell and Coombs' type II DHRs, type III DHRs, and severe cutaneous adverse reactions (SCARs), which are a subtype of type IV DHRs $(5,12)$.

The pathophysiological mechanisms that induce allergenspecific and temporal immunotolerance in $\mathrm{PhI}$ reactions include the inhibition of both the early and late response of the mast cells $(7,13-15)$. Initially it was thought that it was because the internalization of antigen/IgE/Fc\&RI complexes $(7,13,16)$, but recent studies suggest that the main mechanisms include the decrease in some signal transducer molecules such as Syk $(17,18)$, and the recruitment of the inositol phosphatase SHIP-1 into the plasma membrane, which could tip the balance between positive and negative signaling pathways that regulate degranulation (19).

On the other hand, the mechanisms for achieving tolerance during desensitizations in NIDHRs are poorly understood; previous studies have pointed to the activation of $\mathrm{T}$ lymphocytes as the main endotype $(20,21)$. In fact, one study of fixed drug eruptions suggest that the migration of $\mathrm{CD} 25+\mathrm{CD} 4+\mathrm{T}$ lymphocytes to the lesion during desensitization would modulate the response by suppressing the effector function of the CD8+ T lymphocytes that are responsible for the initial lesion (22).

Recent analysis of cytokines during both IDHR and NIDHR shows substantial increases in IL-10 after desensitization, related to the action of regulatory $\mathrm{T}$ lymphocytes and regulatory $\mathrm{B}$ lymphocytes, meaning that tolerance induced by desensitization implies the modulation of drug-specific response by regulatory mechanisms (23).

Little is known about the mechanisms involved in $\mathrm{CPh}$ reactions. However, a previous series of cases presented in poster form on the European Academy of Allergy and Clinical Immunology Annual Congress, suggested that desensitization could be beneficial in these patients, potentially affecting the switch from NIDHR to IDHR (6).

This study aimed to describe the clinical characteristics of $\mathrm{CPh}$ reactions and their evolution during desensitization, not only with taxanes but also with other chemotherapeutic drugs and monoclonal antibodies (MAb) that have not yet been associated with this phenotype in the literature.

\section{METHODS}

We retrospectively analyzed the medical records of all patients who underwent desensitization to chemotherapeutic or biological drugs at the Alicante General University Hospital between January 2019 and December 2020. Only patients who presented symptoms compatible with $\mathrm{CPh}$ were included in the analysis. Patients with non-immediate, severe skin reactions with systemic symptoms (SCARS) were excluded. The Hospital Ethics Committee approved the study protocol.

We considered a $\mathrm{CPh}$ in patients who experienced an IDHR to chemotherapy or MAbs after having experienced a NIDHR on the previous administration of that same drug (6). DHRs were classified as immediate when symptoms appeared $1 \mathrm{~h}$ to $6 \mathrm{~h}$ after exposure, or as nonimmediate when they appeared at least $6 \mathrm{~h}$ after exposure (8). Previous studies classified IDHRs into phenotypes $\mathrm{PhI}, \mathrm{CRR}, \mathrm{MxPh}$, or either phenotype (EPh) based on clinical symptoms $(24,25)$. Characteristic Type I symptoms include: pruritus, urticaria, angioedema, nasal congestion, sneezing, wheezing, cough, throat tightness, and tongue swelling-all related to the mast cell/basophil activation endotype. Symptoms of CRRs include chest pain, back pain, headache, rigors, other pain, chills, and fever; these are related to the monocytes, macrophages or $\mathrm{T}$ lymphocyte activation endotype. In addition, some non-specific symptoms are associated with both type I reactions and CRRs, making it impossible to differentiate the probable endotypes of the reactions; these include flushing/warmth/erythema, rash, dyspnea, oxygen desaturation, chest tightness, tachycardia, presyncope, syncope, hypertension, hypotension, nausea/vomiting, diarrhea, abdominal pain, bleeding, reflux, numbness/weakness, seizures, unusual taste, and diaphoresis.

Thus, the PhI phenotype involves type I reactions, with or without non-specific symptoms; the CRR phenotype implies CRR symptoms, with or without unspecific symptoms; the $\mathrm{MxPh}$ involves any combination of type I and/or CRR symptoms, with or without unspecific symptoms; and $\mathrm{EPh}$ involves only nonspecific symptoms.

Patient age, sex, diagnosis, history of atopy, previous lifetime exposures to the culprit drug before the initial delayed reaction, interval of the delayed reaction, delayed symptoms, exposures to the culprit drug at the moment of the immediate reaction, grade of the immediate reaction classified according to Brown's grading system (26), results of skin tests (ST), tryptase and IL-6 levels, 
additional changes in the phenotype during the breakthrough reaction (BTR), and desensitization outcomes were assessed.

Atopy was defined as a confirmed history of at least one of the following: allergic rhinitis/asthma, food allergies, contact dermatitis, acute urticaria with an allergic cause, or allergy to Hymenoptera venom. Confirmed and unconfirmed allergies to other drugs were also evaluated.

Skin tests were performed at least 2 weeks after the last DHR, using, at prick level: paclitaxel in concentration of $6 \mathrm{mg} / \mathrm{ml}$, docetaxel $10 \mathrm{mg} / \mathrm{ml}$, carboplatin $10 \mathrm{mg} / \mathrm{ml}$, oxaliplatin $5 \mathrm{mg} / \mathrm{ml}$, rituximab $10 \mathrm{mg} / \mathrm{ml}$, adalimumab $50 \mathrm{mg} / \mathrm{ml}$, and brentuximab 5 $\mathrm{mg} / \mathrm{ml}$. If the prick was negative, dilutions of 1:1,000, 1:100, 1:10, or 1:1 were used for intradermal tests, as described elsewhere $(25,27)$. A wheal with a diameter at least $3 \mathrm{~mm}$ larger than that produced by a negative control (normal saline) and surrounded by erythema within $20 \mathrm{~min}$ of application was considered a positive result. Histamine skin prick testing $(10 \mathrm{mg} / \mathrm{ml})$ was used as a positive control. In addition, a reading took place at 24 and $48 \mathrm{~h}$ after skin testing. In all cases, we advised patients to monitor the delayed response for up to 1 week after testing.

The desensitization protocols used were those proposed by the Brigham and Women's Hospital group, consisting of bags, at different dilutions, administered in $4,8,12$, or 16 steps with 2to 2.5 -fold dose increments, along with increasing infusion rate every $15 \mathrm{~min}$, except in the final step, where it was maintained until the full dose was reached (7).

Based on the symptoms during the IDHRs, premedication was administered $30 \mathrm{~min}$ before desensitization, including cetirizine (10 mg orally) and ranitidine (50 $\mathrm{mg}$ intravenously). Additional premedication included aspirin $300 \mathrm{mg}$ (for flushing) and montelukast $10 \mathrm{mg}$ (for bronchospasm/chest tightness). COX-1 inhibitors, acetaminophen, fluids, and opioids were used to prevent chills, rigors, fever, and pain, while benzodiazepines (alprazolam $0.5 \mathrm{mg}$ ) were administered in case of anxiety. Patients were asked to withhold $\beta$-adrenergic blocking medications for $24 \mathrm{~h}$ before desensitization (10).

If a BTR occurred during desensitization, the infusion was stopped, and medications were administered based on symptoms and severity. Once the reaction resolved, the infusion was resumed at the step where it was stopped. Tryptase and IL- 6 were drawn 30-120 min postreaction.

Serum tryptase and IL-6 levels were available for some patients at baseline and during the first IDHR; however, we were unable to obtain biomarkers for all reactions because other attending health professionals did not always order them, and in some cases there were patient care and time limitations.

Tryptase and IL-6 were determined using commercially available immunoassays following the manufacturer's instructions (Tryptase fluoroimmunoassay, Thermo Fisher Scientific, Uppsala, Sweden; and Elecsys IL-6 Immunoassay, Roche Diagnostics, USA, respectively). A serum tryptase concentration $>11.4 \mu \mathrm{g} / \mathrm{L}$ was considered elevated, as were the values during the reaction which exceeded the product obtained by the formula Basal Tryptase x $1.2+2(28,29)$. IL-6 values more than $10 \mathrm{pg} / \mathrm{ml}$ were also considered elevated.

Descriptive statistics of categorical variables were expressed through absolute and relative counts using frequency tables and graphs. Quantitative variables were described using measures of central tendency (mean and median) and dispersion [standard deviation (SD) and interquartile range (IQR) and/or range]. We used the IBM SPSS Statistics program, version 27 (IBM Corp., Armonk, N.Y., USA).

\section{RESULTS}

Of the 116 patients evaluated for DHR to chemotherapeutic and biological drugs, $12(10.3 \%)$ met criteria for $\mathrm{CPh}: 3(25 \%)$ had reactions to paclitaxel, 3 (25\%) to docetaxel, $2(16.7 \%)$ to rituximab, $1(8.3 \%)$ to adalimumab, $1(8.3 \%)$ to brentuximab, 1 (8.3\%) to carboplatin, and $1(8.3 \%)$ to oxaliplatin.

Most $(91.7 \%)$ of the included patients were women, and the mean age at diagnosis was 41 (SD 13.6) years. Ten (83.3\%) patients were diagnosed with cancer ( 3 ovarian, 3 breast, 2 lymphomas, 1 endometrial cancer, and 1 gastric cancer), and two had autoimmune diseases (Crohn's disease and multiple sclerosis). Atopy was present in $80 \%$ of the patients.

The median number of drug exposures at the time of the NIDHR was 2.1 (range 0-16), and the median interval between drug exposure and reaction was $90.6 \mathrm{~h}$ (range 8-288 h). Patients reacting to taxanes had the least historical exposure to these drugs $(83.3 \%$ had a reaction on their first exposure), while the carboplatin-allergic patient had been the most exposed (16 previous exposures prior to DHR). Table 1 summarizes the characteristics of the patients and the NIDHRs.

At the time of conversion, the mean exposure before developing the IDHR was 3.8 (range 1-17) and the phenotypes expressed during the IDHR were PhI $(n=7 ; 58.3 \%)$, CRR $(n=$ $4 ; 33.3 \%)$ and $\mathrm{EPh}(n=1 ; 8.3 \%)$.

The seven patients expressing $\mathrm{PhI}$ had an average of five prior lifetime exposures, most of which were grade (G) 2 (57.1\%) or G3 (28.6\%); the remaining $14.3 \%$ had a G1 reaction. Skin tests were positive in 6 (85.7\%) patients. Reactions were mainly (57.1\%) triggered by biological drugs ( 2 rituximab, 1 adalimumab, 1 brentuximab), followed by platins (28.6\%: 1 carboplatin and 1 oxaliplatin) and taxanes (14.3\%, 1 docetaxel) (Table 2).

On the other hand, patients who developed CRRs had an average of 1.3 exposures to the drug at the time of the IDHR, all corresponding to taxanes (50\% to paclitaxel and 50\% to docetaxel), with G2 reactions and negative STs.

Finally, one patient with an EPh developed a G2 reaction during the second exposure to paclitaxel, with a negative skin test. Clinical characteristics are summarized in Table 2.

Regardless of phenotype, none of the patients had positive results on the delayed reading of the skin tests.

Altogether, 51 desensitizations were done, and all (100\%) of the treatments were completed. There were 10 (19.6\%) BTRs: 7 (70\%) of which were immediate and $3(30 \%)$ non-immediate.

Regarding the phenotype expressed during the immediate BTRs, 5 (85.7\%) were PhI, and 1 (14.3\%) Eph; all were of the same phenotype as the IDHRs. On the other hand, nonimmediate BTRs came from CRR in two patients who developed warmth and back pain some hours after desensitization. One carboplatin-allergic patient (patient 9 in all tables), developed 
TABLE 1 | Characteristics of included patients and non-immediate drug hypersensitivity reactions.

\begin{tabular}{|c|c|c|c|c|c|c|c|c|c|c|c|}
\hline Case & Sex & $\begin{array}{c}\text { Age } \\
\text { (years) }\end{array}$ & Ethnicity & Diagnosis & Stage & Type & Culprit drug & $\begin{array}{c}N \text { exposures } \\
\text { before } \\
\text { delayed } \\
\text { reaction }\end{array}$ & $\begin{array}{c}\text { Reaction } \\
\text { interval } \\
\text { (hours) }\end{array}$ & Delayed symptoms & Atopy \\
\hline 1 & $\mathrm{~F}$ & 39 & White & Crohn's disease & NA & NA & Adalimumab & 6 & 11 & $\begin{array}{l}\text { Erythema and swelling } \\
\text { at injection site }\end{array}$ & $\begin{array}{l}\text { Allergic rhinitis, } \\
\text { drug allergy, } \\
\text { urticaria }\end{array}$ \\
\hline 3 & $\mathrm{~F}$ & 40 & White & Ovarian cancer & III & Primary & Paclitaxel & 1 & 13 & $\begin{array}{l}\text { Maculopapular } \\
\text { exanthema }\end{array}$ & Drug allergy \\
\hline 4 & $\mathrm{~F}$ & 47 & White & Breast cancer & $\|$ & Primary & Docetaxel & 0 & 8 & Flushing & $\begin{array}{l}\text { Allergic rhinitis, } \\
\text { drug allergy }\end{array}$ \\
\hline 5 & $\mathrm{~F}$ & 48 & White & Ovarian cancer & IV & Primary & Paclitaxel & 0 & 72 & $\begin{array}{l}\text { Maculopapular } \\
\text { exanthema }\end{array}$ & $\begin{array}{l}\text { Allergic rhinitis, } \\
\text { drug allergy }\end{array}$ \\
\hline 8 & $\mathrm{~F}$ & 50 & White & Breast cancer & $\|$ & Primary & Docetaxel & 0 & 72 & $\begin{array}{l}\text { Maculopapular } \\
\text { exanthema, abdominal } \\
\text { pain, chest tightness }\end{array}$ & Allergic rhinitis \\
\hline 9 & $\mathrm{~F}$ & 64 & White & $\begin{array}{l}\text { Endometrial } \\
\text { cancer }\end{array}$ & IV & Recurrent & Carboplatin & 16 & 48 & Flushing, pruritus & $\begin{array}{l}\text { Allergic rhinitis, } \\
\text { drug allergy }\end{array}$ \\
\hline 10 & F & 41 & White & Breast cancer & NA & Primary & Docetaxel & 0 & 120 & Chest pain & Allergic rhinitis \\
\hline 11 & F & 25 & Hispanic & Gastric cancer & IV & Primary & Oxaliplatin & $2^{*}$ & 120 & $\begin{array}{l}\text { Palmoplantar } \\
\text { erythema, scaling }\end{array}$ & - \\
\hline 12 & M & 58 & White & $\begin{array}{l}\text { B-cell } \\
\text { non-Hodgkin } \\
\text { lymphoma }\end{array}$ & $\|$ & Primary & Rituximab & 0 & 288 & $\begin{array}{l}\text { Fever, maculopapular } \\
\text { exanthema, malaise, } \\
\text { myalgia, arthralgia }\end{array}$ & - \\
\hline
\end{tabular}

F, female; M, male; NA, not applicable/available. ${ }^{*} T$ his patient tolerated 2 doses without problems, however from the 3th dose to the 6th dose developed with each exposure a NIDHR with the characteristics described.

a non-immediate BTR with fever and back pain a few hours after desensitization was completed; this patient developed an immediate $\mathrm{PhI}$ reaction during desensitization (Table 3). There were no immediate life-threatening or severe NIDHRs during or after desensitization.

Serum levels of tryptase and IL- 6 were quantified in 5 out of 7 (71.4\%) BTRs during desensitization. Two patients presented significant elevations of tryptase, including patient 11 , allergic to oxaliplatin, who was identified by applying the formula (Basal Tryptase $\times 1.2+2$ ); both elevations corresponded to $\mathrm{PhI}$ reactions. In addition to the increase in tryptase, a slight elevation of IL-6 was demonstrated during an immediate BTR; this patient had a non-immediate BTR suggestive of CRR several hours after finishing desensitization (Table 3).

\section{DISCUSSION}

The phenotype-based approach of precision medicine allows us to predict how patients will respond to treatment (7). We described the clinical characteristics of the $\mathrm{CPh}$ reactions and their evolution during the desensitization of several drugs that shared the appearance of an NIDHR but which, after successive exposures the phenotype, changed into IDHRs (6). Based on our observations, we make a series of recommendations on the allergological workup for this phenotype.

The characteristic change in the $\mathrm{CPh}$ makes it unique. Previous publications by Gómez et al. (2) and Torres et al. (3) describe accelerated reactions which appear 1-48 h after exposure to the drug, without associated changes in the phenotype and with evidence that the endotype involved in them is the activation of $\mathrm{T}$ lymphocytes. Our results suggest that initial $\mathrm{CPh}$ reactions always appear at least $6 \mathrm{~h}$ after exposure, fulfilling the criteria for an NIDHR (8). Thus, CPh is not a subtype of accelerated reactions, and the mechanisms that provoke them should be investigated.

In these patients, NIDHRs often developed on the first exposure to the drug and were characterized by the appearance of non-severe symptoms including maculopapular exanthema, erythema, and flushing. Several days after exposure, some patients also developed symptoms suggestive of cytokine release such as back pain, myalgias, arthralgias, chest tightness, and fever.

We showed that after developing an NIDHR, at least one subsequent exposure was needed before changing the phenotype to develop an IDHR. Most patients developed PhI 
TABLE 2 | Characteristics of included patients at the moment of conversion to immediate hypersensitivity reactions.

\begin{tabular}{|c|c|c|c|c|c|c|c|c|c|c|}
\hline Case & $\begin{array}{c}\text { Baseline } \\
\text { tryptase } \\
(\mu \mathrm{g} / \mathrm{L})\end{array}$ & $\begin{array}{l}\text { Baseline } \\
\text { IL-6 } \\
\text { (pg/mL) }\end{array}$ & $\begin{array}{l}\text { Culprit } \\
\text { drug }\end{array}$ & $\begin{array}{l}\mathrm{N} \text { exposures } \\
\text { before } \\
\text { immediate } \\
\text { reaction }\end{array}$ & Immediate symptoms & Phenotype & $\begin{array}{l}\text { Grade } \\
\text { severity }\end{array}$ & $\begin{array}{l}\text { Tryptase } \\
\text { during } \\
\text { IDHR } \\
(\mu \mathrm{g} / \mathrm{L})\end{array}$ & $\begin{array}{c}\text { IL-6 } \\
\text { during IDHR } \\
\text { (pg/mL) }\end{array}$ & Skin test \\
\hline 1 & 4.9 & & Adalimumab & 7 & $\begin{array}{l}\text { Angioedema, pruritus, } \\
\text { erythema }\end{array}$ & $\mathrm{Phl}$ & 2 & & & + \\
\hline 2 & 6.2 & & Paclitaxel & 1 & $\begin{array}{l}\text { Flushing, back pain, chest } \\
\text { tightness, abdominal pain }\end{array}$ & CRR & 2 & & & - \\
\hline 4 & 4.5 & & Docetaxel & 1 & $\begin{array}{l}\text { Flushing, pruritus, dyspnea, } \\
\text { chest tightness, oxygen } \\
\text { desaturation, abdominal } \\
\text { pain, tremors, dizziness }\end{array}$ & $\mathrm{Phl}$ & 3 & & & + \\
\hline 5 & 2.6 & & Paclitaxel & 1 & $\begin{array}{l}\text { Warmth, chest tightness, } \\
\text { hypertension }\end{array}$ & $\mathrm{EPh}$ & 2 & & & - \\
\hline 8 & 3 & $<2$ & Docetaxel & 1 & Flushing, fever & CRR & 2 & 4.2 & 78 & - \\
\hline 9 & 5.6 & 9 & Carboplatin & 17 & $\begin{array}{l}\text { Pruritus, flushing, chest } \\
\text { tightness, dyspnea, } \\
\text { tachycardia, blurred vision, } \\
\text { diaphoresis, fainting }\end{array}$ & $\mathrm{Phl}$ & 2 & & & + \\
\hline 10 & & & Docetaxel & 1 & $\begin{array}{l}\text { Back pain, chest pain, chest } \\
\text { tightness, dyspnea, } \\
\text { dizziness, fainting }\end{array}$ & CRR & 2 & & & - \\
\hline 11 & 3 & 4 & Oxaliplatin & 7 & $\begin{array}{l}\text { Burning feeling, pruritus, } \\
\text { sialorrhea, nasal blockage, } \\
\text { cough, dyspnea, nausea, } \\
\text { vomiting, blurred vision }\end{array}$ & $\mathrm{Phl}$ & 2 & & & + \\
\hline
\end{tabular}

IL-6, interleukin 6; IDHR, Immediate drug hypersensitivity reaction; Phl, phenotype I; CRR, cytokine release reactions; EPh, either phenotype.

reactions, especially those treated with platins $(24,25,30)$, who presented the highest number of exposures, followed by MAb (27), supporting previous observations that indicate that IgE mediation is a fundamental mechanism in the development of DHRs to these drugs $(9,24,27)$.

On the other hand, almost all taxane-treated patients developed CRR during the first exposures. Patients who converted from an NIDHR to PhI reaction had mostly presented with symptoms such as myalgia, arthralgia, malaise, and fever, while those who developed CRR had presented maculopapular exanthema, chest tightness or pain. These findings suggest that during NIDHRs, different cytokines on which the symptoms depend could be released. In the first group, the release of IFN- $\gamma$ would predominate, while in the second group excessive amounts of other cytokines such as IL-6, TNF- $\alpha$ and IL-10 would be produced (31).

Regarding desensitization, the overall efficacy we observed, at $80.4 \%$, was better than in previous publications, where it ranged from $74 \%$ (32) to $76.8 \%$ (27), which a priori suggests that this phenotype does not cause more BTRs. Our results support the idea that desensitization prevents the reappearance of serious, potentially life-threatening immediate reactions (33).

In addition, during BTRs we did not observe new changes in the phenotypes. Moreover, compared to Silver et al. (24), in our study patients who presented CRRs responded better to desensitization, perhaps due to the possible effect of desensitization on the components of the Src complex, present not only in mast cells but also in other cells of the innate immune system (34-36).

Regarding biomarkers, skin tests were very useful for identifying $\mathrm{PhI}$ reactions, even in patients who reacted after few exposures to the drugs. On the other hand, elevation of serum tryptase and IL-6 were related to the phenotypes involved in the reaction, supporting the idea that they are useful in the endophenotyping of the reactions $(1,11)$. In this sense, one patient who presented PhI BTR had a significant elevation of tryptase and a slight increase in IL-6, and hours later developed symptoms suggestive of cytokine release, which could be secondary to a delayed release of mediators by mast cells. 
TABLE 3 | Characteristics of the desensitizations.

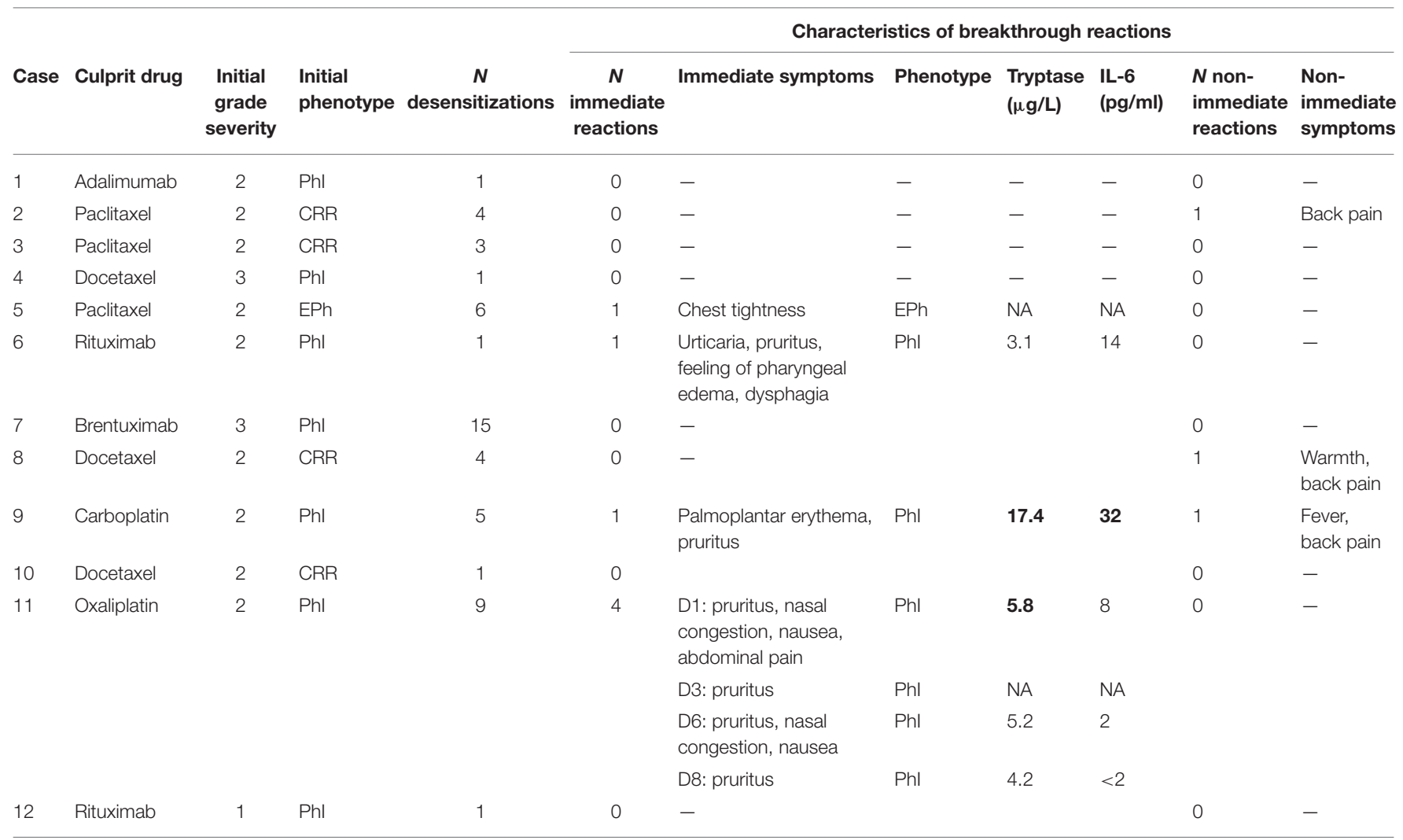

IL-6, interleukin 6; D1, desensitization 1; D3, desensitization 3; etc.; NA, not available; Phl, phenotype l; CRR, cytokine release reactions; EPh, either phenotype.

Values in bold indicate significant elevations either above the reference limit or when the tryptase value during the reaction was greater than (BT $\times 1.2)+2$.

Previous observations about $\mathrm{CPh}$ suggest that the proper allergology workup after the NIDHRs using in vivo and in vitro tests (including skin test, patch tests and/or the quantification of biomarkers) could inform the decision on which patients would benefit from a challenge or desensitization (37) in order to avoid progression from a non-immediate to an immediate reaction (6). Although the information that can be gleaned from these tests is limited, the cytokine release enzyme linked to the ImmunoSpot (ELISpot) assay could be useful to identify the endotype in these reactions (38).

Finally, although our objective was not to clarify the mechanisms by which $\mathrm{CPh}$ could develop, our observations allow us to hypothesize. A logical explanation involves both innate and acquired immunity. During the NIDHR, the cytokines released would be responsible for the symptoms and for the polarization of the reaction, triggering a Th1 response with the subsequent appearance of a CRR in successive exposures, or on the contrary the cytokines could produce a Th2 response, responsible for the activation of mast cells as an IgEmediated response. There are connection pathways between mast cells and macrophages that could explain mixed phenotypes (Figure 1).

This descriptive study has several limitations. Firstly, our cohort is not representative of all patients with $\mathrm{CPh}$ because not all those who developed NIDHR were rechallenged, and some patients who finally changed their phenotype were not sent to evaluation by the allergist. Secondly, the size of the sample and the heterogeneity of the patients and drugs involved limit the performance of a robust statistical analysis and the extrapolation of the data. Thirdly, intravenous chemotherapeutic and biological agents are highly sensitizing drugs and the IDHR experienced by these patients could potentially be unrelated to the previous NIDHR. Finally, we did not use experimental methods that would allow us to verify our hypothesis, so we recommend carrying out basic studies that make it possible to elucidate the mechanisms that could be involved in this potential $\mathrm{CPh}$ as described in our study.

\section{CONCLUSIONS}

Summarizing, $\mathrm{CPh}$ denotes a set of reactions characterized by an initial NIDHR and subsequent IDHRs after repeated exposures. These reactions, which had initially been described after exposure to taxanes, present a similar pattern after administration of other drugs, including platins and MAb.

The symptoms presented during the NIDHR may indicate the need for an early allergological evaluation to assess the risk of future IDHRs. Rapid drug desensitization could prevent 


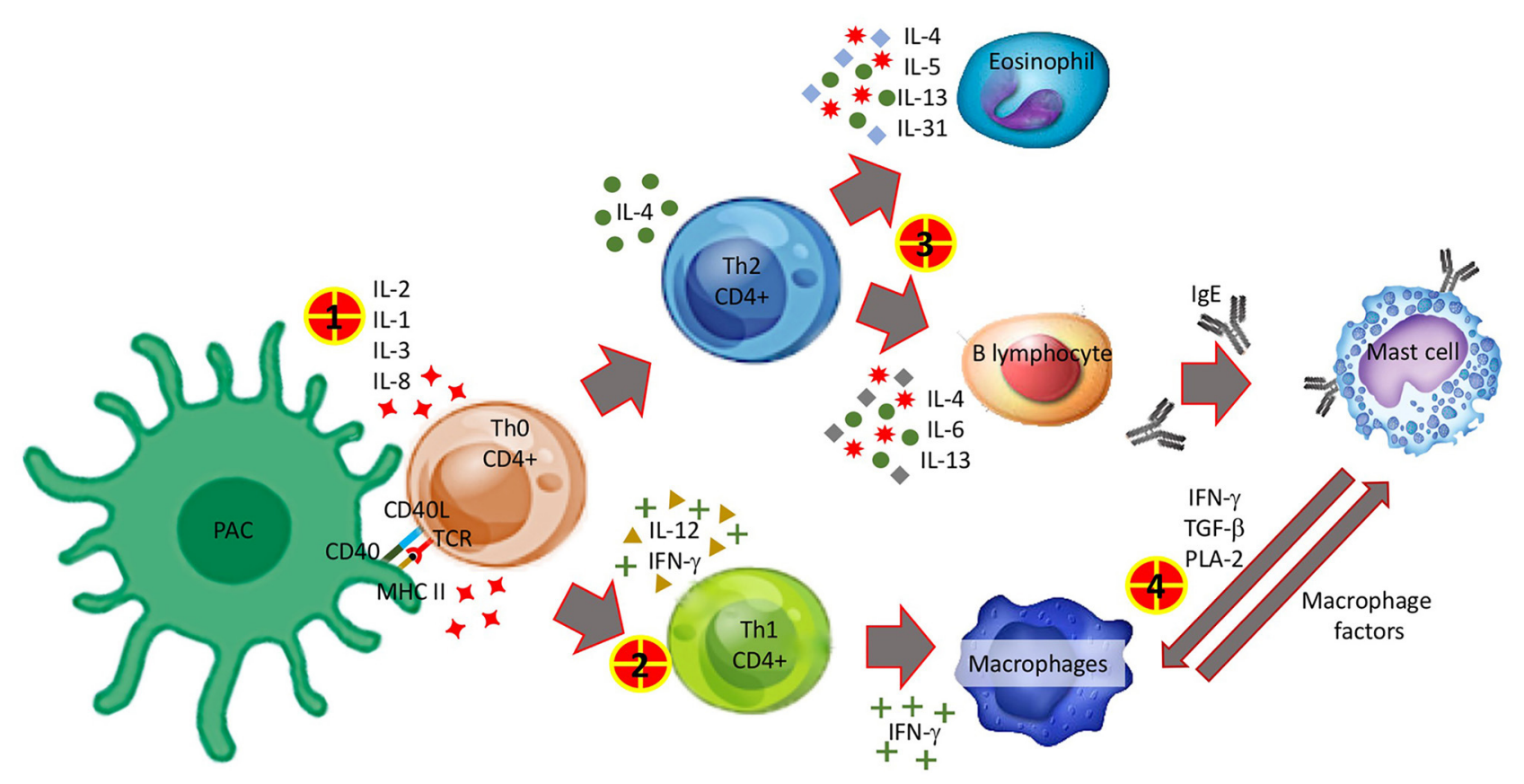

FIGURE 1 | Possible mechanisms involved in the appearance of the converter phenotype. 1 Interleukins released after antigen presentation and lymphocyte differentiation to CD4+ Th1 and Th2 may be related to the occurrence of non-immediate reactions. 2 Th1 polarization. 3 Th2 polarization. 4 The pathway by which macrophages and monocytes are activated in cytokine release reactions is not entirely clear. On the one hand, it could be a non-predominant activation of Th1 that would allow these cells to discharge a large amount of cytokines responsible for the symptoms and, on the other hand, mast cells would establish a bridge with these and other cells of the innate immune system by releasing more cytokines that would amplify the immune response and contribute to symptoms.

conversion or, if this has already occurred, prevent the recurrence of serious or life-threatening immediate reactions.

The clinical characteristics of reactions, skin test results, and biomarkers can help predict responses to rapid drug desensitization, guiding clinicians on how to optimize therapy delivery while maintaining patient safety.

\section{DATA AVAILABILITY STATEMENT}

The original contributions presented in the study are included in the article/supplementary material, further inquiries can be directed to the corresponding author/s.

\section{ETHICS STATEMENT}

The studies involving human participants were reviewed and approved by Ethics Committee for Research with Medicines of the Alicante Department of Health. The patients/participants

\section{REFERENCES}

1. Jimenez-Rodriguez TW, Garcia-Neuer M, Alenazy LA, Castells M. Anaphylaxis in the 21st century: phenotypes, endotypes, and biomarkers. J Asthma Allergy. (2018) 11:121-42. doi: 10.2147/JAA.S1 59411 provided their written informed consent to participate in this study.

\section{AUTHOR CONTRIBUTIONS}

TWJ-R, IL-C, RM-A, VS-G, PG-D, and JF-S contributed to conception and design of the study. FM, RM-A, and NM-B coordinated the data collection. FM analyzed the biomarkers results. RM-A, AB-SJ, SC-B, and NM-B organized the database and analyzed the results. TWJ-R wrote the first draft of the manuscript. All authors contributed to manuscript revision, read, and approved the submitted version.

\section{ACKNOWLEDGMENTS}

The authors would like to thank Allergy Therapeutics Iberica, S.L.U., who were sponsors for the payment of the fees for this publication. The authors gratefully thank Meggan Harris for excellent technical assistance.

2. Gómez E, Blanca-Lopez N, Salas M, Canto G, Campo P, Torres $\mathrm{MJ}$, et al. Induction of accelerated reactions to amoxicillin by T-cell effector mechanisms. Ann Allergy Asthma Immunol. (2013) 110:267-73. doi: 10.1016/j.anai.2013.01.003

3. Torres MJ, Salas M, Ariza A, Fernández TD. Understanding the mechanisms in accelerated drug reactions. Curr Opin Allergy 
Clin Immunol. (2016) 16:308-14. doi: 10.1097/ACI.00000000000 00285

4. Demoly P, Adkinson NF, Brockow K, Castells M, Chiriac AM, Greenberger PA, et al. International Consensus on drug allergy. Allergy. (2014) 69:420-37. doi: 10.1111/all.12350

5. Scherer K, Brockow K, Aberer W, Gooi JHC, Demoly P, Romano A, et al. Desensitization in delayed drug hypersensitivity reactions - an EAACI position paper of the Drug Allergy Interest Group. Allergy. (2013) 68:844-52. doi: 10.1111/all.12161

6. Jimenez-Rodriguez TW, Alvarez Labella M, Garcia-Neuer M, Lynch DMM, Castells M. Abstract 1769 delayed hypersensitivity reactions to taxane can progress to Type I reactions: management with desensitization. Allergy. (2018) 73:811. doi: 10.1111/all.13540

7. de Las Vecillas Sánchez L, Alenazy LA, Garcia-Neuer M, Castells MC. Drug hypersensitivity and desensitizations: mechanisms and new approaches. Int J Mol Sci. (2017) 18:1316. doi: 10.3390/ijms180 61316

8. Broyles AD, Banerji A, Castells M. Practical guidance for the evaluation and management of drug hypersensitivity: general concepts. J Allergy Clin Immunol Pract. (2020) 8:S3-15. doi: 10.1016/j.jaip.2020. 08.002

9. Caiado J, Brás R, Paulino M, Costa L, Castells M. Rapid desensitization to antineoplastic drugs in an outpatient immunoallergology clinic. Ann Allergy Asthma Immunol. (2020) 125:325-33. doi: 10.1016/j.anai.2020. 04.017

10. Yang BC, Castells M. Diagnosis and treatment of drug hypersensitivity reactions to biologicals: medical algorithm. Allergy. (2020) 75:3293-6. doi: 10.1111/all.14432

11. Jakubovic BD, Sanchez-Sanchez S, Hamadi S, Lynch D, Castells M. Interleukin-6: a novel biomarker for monoclonal antibody and chemotherapy-associated hypersensitivity confirms a cytokine release syndrome phenotype-endotype association. Allergy. (2021) 76:1571-3. doi: 10.1111/all.14644

12. Tuttle KL, Stavrou E, Hong DIC, Connell NT, Wickner P. Oxaliplatin hypersensitivity complicated by thrombocytopenia during desensitization. Ann Allergy Asthma Immunol. (2021) 127:267-9. doi: 10.1016/j.anai.2021.04.032

13. Sancho-Serra M del C, Simarro M, Castells M. Rapid IgE desensitization is antigen specific and impairs early and late mast cell responses targeting Fc\&RI internalization. Eur J Immunol. (2011) 41:1004-13. doi: 10.1002/eji.2010 40810

14. Ang WXG, Church AM, Kulis M, Choi HW, Burks AW, Abraham SN. Mast cell desensitization inhibits calcium flux and aberrantly remodels actin. J Clin Invest. (2016) 126:4103-18. doi: 10.1172/JCI87492

15. Morales AR, Shah N, Castells M. Antigen-IgE desensitization in signal transducer and activator of transcription 6-deficient mast cells by suboptimal doses of antigen. Ann Allergy Asthma Immunol. (2005) 94:575-80. doi: 10.1016/S1081-1206(10)61136-2

16. Oka T, Rios EJ, Tsai M, Kalesnikoff J, Galli SJ. Rapid desensitization induces internalization of antigen-specific IgE on mouse mast cells. J Allergy Clin Immunol. (2013) 132:922-32. doi: 10.1016/j.jaci.2013. 05.004

17. Zhao W, Gomez G, Macey M, Kepley CL, Schwartz LB. In vitro desensitization of human skin mast cells. J Clin Immunol. (2012) 32:150-60. doi: 10.1007/s10875-011-9605-8

18. MacGlashan D, Miura K. Loss of syk kinase during IgE-mediated stimulation of human basophils. J Allergy Clin Immunol. (2004) 114:1317-24. doi: 10.1016/j.jaci.2004.08.037

19. Alenazy LA, de las Vecillas Sanchez L, Jimenez Rodriguez TW, FalckFuentes CA, Castells MC. Phosphatases in mouse mast cells rapid IgE desensitization: the role of SHIP-1. J Allergy Clin Immunol. (2018) 141:AB192. doi: 10.1016/j.jaci.2017.12.610

20. Karmacharya P, Poudel DR, Pathak R, Donato AA, Ghimire S, Giri S, et al. Rituximab-induced serum sickness: a systematic review. Semin Arthritis Rheum. (2015) 45:334-40. doi: 10.1016/j.semarthrit.2015.06.014

21. Chen C-B, Wu M-Y, Ng CY, Lu C-W, Wu J, Kao P-H, et al. Severe cutaneous adverse reactions induced by targeted anticancer therapies and immunotherapies. Cancer Manag Res. (2018) 10:1259-73. doi: 10.2147/CMAR.S163391

22. Teraki Y, Shiohara T. Successful desensitization to fixed drug eruption: the presence of CD25+CD4+ T cells in the epidermis of fixed drug eruption lesions may be involved in the induction of desensitization. Dermatology. (2004) 209:29-32. doi: 10.1159/000078583

23. Vultaggio A, Matucci A, Nencini F, Bormioli S, Vivarelli E, Maggi E. Mechanisms of drug desensitization: not only mast cells. Front Pharmacol. (2020) 11:1-6. doi: 10.3389/fphar.2020.590991

24. Silver J, Garcia-Neuer M, Lynch D-M, Pasaoglu G, Sloane DE, Castells M. Endophenotyping oxaliplatin hypersensitivity: personalizing desensitization to the atypical platin. J Allergy Clin Immunol Pract Pract. (2020) 8:1668-80. doi: $10.1016 /$ j.jaip.2020.02.013

25. Vega A, Jimenez-Rodriguez T, Barranco R, Bartra J, Diéguez $M$, Doña I, et al. Hypersensitivity reactions to cancer chemotherapy: practical recommendations of ARADyAL for diagnosis and desensitization. J Investig Allergy Clin Immunol. (2021) 31:364-84. doi: 10.18176/jiaci.0712

26. Brown SGA. Clinical features and severity grading of anaphylaxis. J Allergy Clin Immunol. (2004) 114:371-6. doi: 10.1016/j.jaci.2004. 04.029

27. Isabwe GAC, Garcia Neuer M, de Las Vecillas Sanchez L, Lynch D-M, Marquis K, Castells M. Hypersensitivity reactions to therapeutic monoclonal antibodies: phenotypes and endotypes. J Allergy Clin Immunol. (2018) 142:159-70. doi: 10.1016/j.jaci.2018.02.018

28. Valent P, Bonadonna P, Hartmann K, Broesby-Olsen S, Brockow K, Butterfield $\mathrm{JH}$, et al. Why the $20 \%+2$ tryptase formula is a diagnostic gold standard for severe systemic mast cell activation and mast cell activation syndrome. Int Arch Allergy Immunol. (2019) 180:44-51. doi: 10.1159/0005 01079

29. Vitte J, Sabato V, Tacquard C, Garvey LH, Michel M, Mertes PM, et al. Use and interpretation of acute and baseline tryptase in perioperative hypersensitivity and anaphylaxis. J Allergy Clin Immunol Pract. (2021) 9:29943005. doi: 10.1016/j.jaip.2021.03.011

30. Madrigal-Burgaleta R, Bernal-Rubio L, Berges-Gimeno MP, Carpio-Escalona LV, Gehlhaar P, Alvarez-Cuesta E. A large single-hospital experience using drug provocation testing and rapid drug desensitization in hypersensitivity to antineoplastic and biological agents. J Allergy Clin Immunol Pract. (2019) 7:618-32. doi: 10.1016/j.jaip.2018.07.031

31. Shimabukuro-Vornhagen A, Gödel P, Subklewe M, Stemmler HJ, Schlößer HA, Schlaak M, et al. Cytokine release syndrome. J Immunother Cancer. (2018) 6:56. doi: 10.1186/s40425-018-0343-9

32. Sloane D, Govindarajulu U, Harrow-Mortelliti J, Barry W, Hsu FI, Hong D, et al. Safety, costs, and efficacy of rapid drug desensitizations to chemotherapy and monoclonal antibodies. J Allergy Clin Immunol Pract. (2016) 4:497-504. doi: 10.1016/j.jaip.2015.12.019

33. Jakubovic BD, Vecillas L de Las, Jimenez-Rodriguez TW, SanchezSanchez S, Castells M. Drug hypersensitivity in the fast lane: what clinicians should know about phenotypes, endotypes, and biomarkers. Ann Allergy Asthma Immunol. (2020) 124:566-72. doi: 10.1016/j.anai.2020. 04.005

34. Futosi K, Fodor S, Mócsai A. Neutrophil cell surface receptors and their intracellular signal transduction pathways. Int Immunopharmacol. (2013) 17:638-50. doi: 10.1016/j.intimp.2013.06.034

35. Zhu J, Luo L, Tian L, Yin S, Ma X, Cheng S, et al. Aryl hydrocarbon receptor promotes IL-10 expression in inflammatory macrophages through Src-STAT3 signaling pathway. Front Immunol. (2018) 9:1-14. doi: 10.3389/fimmu.2018.02033

36. Cui J, Chen Y, Wang HY, Wang R, Cui J, Chen Y, et al. Mechanisms and pathways of innate immune activation and regulation in health and cancer Mechanisms and pathways of innate immune activation and regulation in health and cancer. (2017) 5515:3270-85. doi: 10.4161/21645515.2014. 979640

37. Madrigal-Burgaleta R, Vazquez-Revuelta P, Marti-Garrido J, Lleonart R, Ali FR, Alvarez-Cuesta E. Importance of diagnostics prior to desensitization in new drug hypersensitivity: chemotherapeutics and biologicals. Curr Treat Options Allergy. (2020) 7:1-13. doi: 10.1007/s40521-020-0 $0238-\mathrm{y}$ 
38. Copaescu A, Gibson A, Li Y, Trubiano JA, Phillips EJ. An updated review of the diagnostic methods in delayed drug hypersensitivity. Front Pharmacol. (2021) 11:1-14. doi: 10.3389/fphar.2020.573 573

Conflict of Interest: The authors declare that the research was conducted in the absence of any commercial or financial relationships that could be construed as a potential conflict of interest.

Publisher's Note: All claims expressed in this article are solely those of the authors and do not necessarily represent those of their affiliated organizations, or those of the publisher, the editors and the reviewers. Any product that may be evaluated in this article, or claim that may be made by its manufacturer, is not guaranteed or endorsed by the publisher.

Copyright $\odot 2022$ Jimenez-Rodriguez, Manuel Marco de la Calle, Lozano-Cubo, Montoyo-Anton, Soriano-Gomis, Gonzalez-Delgado, Burgos-San José, ClimentBallester, Martínez-Banaclocha and Fernández-Sanchez. This is an open-access article distributed under the terms of the Creative Commons Attribution License (CC $B Y)$. The use, distribution or reproduction in other forums is permitted, provided the original author(s) and the copyright owner(s) are credited and that the original publication in this journal is cited, in accordance with accepted academic practice. No use, distribution or reproduction is permitted which does not comply with these terms. 